\title{
Discriminação Salarial Feminina e o Prêmio Salarial de TI na Indústria de Tecnologia da Região Sul*
}

\section{Female Wage Discrimination and the IT Wage Premium in the Southern Brazilian Technology Clusters}

\author{
Patricia Bonini** \\ Fernando Pozzobon***
}

\begin{abstract}
Resumo: Este artigo fornece uma análise do perfil de salário, produtividade e gênero da força de trabalho nas indústrias de transformação e de informação e comunicação, nos polos tecnológicos da região sul brasileira. Aos dados da Relação Anual de Informações Sociais (RAIS), de 2011, é aplicada uma metodologia baseada na economia da discriminação e método de decomposição de Oaxaca. Os resultados da análise econométrica sugerem que existe discriminação salarial feminina na indústria enfocada, nos três estados da região, sendo o Rio Grande do Sul o estado com maior desvantagem salarial feminina e o Paraná, com a menor desvantagem. Além disso, o recorte ocupacional, que separa os analistas de TI de um conjunto mais amplo de 726 ocupações, evidencia que a média salarial dos analistas de TI é maior do que a média das demais ocupações, indicando a vantagem salarial da carreira de analista de TI. Também é evidenciado que os empregos de analistas de TI constituem um território predominantemente masculino, uma vez que a participação feminina é de apenas $22 \%$, na média da região sul. Porém, a vantagem salarial dos analistas de TI é maior para as mulheres do que para os homens, o que implica um menor grau de discriminação feminina para as analistas de TI. Esse resultado, encontrado nos três estados da região sul, se alinha à evidência reportada na literatura para os países da OCDE e é inédito em termos da literatura para a economia brasileira.
\end{abstract}

Palavras-chave: Discriminação salarial feminina. Polos tecnológicos. Prêmio salarial TI.

\begin{abstract}
In this paper we provide an analysis of the wage, productivity and gender profile of the labor force in the manufacturing and information-communication industries, located at the technology clusters in the southern Brazilian states. A methodology based on the economics of discrimination and Oaxaca decomposition is applied to data drawn from RAIS (a statistic office of the Brazilian Labor Office) for the year 2011. The results of the econometric analysis point out the existence of female wage discrimination, being the Rio Grande do Sul the state where women have the

\footnotetext{
* Os autores agradecem ao trabalho dos bolsistas de pesquisa, Guilherme Cemin de Paula e Vanessa Grudtner.

** Doutora em Economia pela University of Birmingham, Reino Unido. Professora adjunta do Departamento de Economia da Universidade do Estado de Santa Catarina (Udesc). E-mail: patriciabonini@gmail.com

*** $\quad$ Mestre em Economia pela Universidade Federal de Pernambuco. Professor assistente do Departamento de Economia da Universidade do Estado de Santa Catarina (Udesc). E-mail: fernando.esag@gmail.com
} 
highest wage disadvantage, while Paraná state show the lowest female disadvantage. Furthermore, in separating the IT analyst workers from a broader group of occupations, we find that the IT workers command a higher average wage, illustrating a career wage advantage. Moreover, despite being underrepresented in the field, as they account for only $22 \%$ of the IT workers, women are able to attain an occupation wage advantage greater than their male counterparts. As a result, the degree of female discrimination is downplayed in the IT careers. These results are in line with empirical findings for the OECD countries and are pioneer for Brazilian data.

Keywords: Female wage discrimination. Technology clusters. IT wage premium. JEL Classification: J16; J71; L86

\section{1 lntrodução}

A integração das mulheres no contingente de população economicamente ativa é um fenômeno relativamente recente e marcado tanto pela desvantagem salarial feminina, quanto pela heterogeneidade da participação feminina no mercado de trabalho. Em especial, os empregos em áreas de aplicação direta de ciência e tecnologia - nos Estados Unidos e Europa, referidas como Science, Technology, Engeneering and Math (STEM) ${ }^{1}$ - são majoritariamente ocupados por homens. Em 2009, as mulheres representavam apenas 24\% dos empregados STEM nos Estados Unidos, embora já fossem 48\% da força de trabalho do país (BEEDE, 2011).

Nas economias desenvolvidas e emergentes, a demanda por trabalho nas áreas STEM tem crescido mais do que a demanda nas outras áreas do mercado de trabalho, enquanto a oferta de trabalhadores nessas áreas se mantém constante (BEEDE, 2011b). Como resultado, a média salarial dos trabalhadores nas áreas STEM é maior do que a média do mercado de trabalho como um todo. Na economia americana, em 2010, o salário médio dos empregos STEM era 26\% maior do que a média dos demais postos de trabalho, vantagem esta que tem sido chamada na literatura pertinente de prêmio STEM. ${ }^{2}$ Adicionalmente, tem chamado a atenção o fato de que as mulheres possuem reduzida participação nos empregos STEM. No entanto, o prêmio STEM feminino é maior do que o masculino, o que implica um menor grau de grau de discriminação salarial feminina nas carreiras STEM.

A principal contribuição deste artigo é mostrar que esse padrão observado nas economias desenvolvidas ocorre também na região sul brasileira, no caso específico dos empregos de analistas de TI. Para tanto, o artigo se constrói em torno do objetivo de avaliar o grau de discriminação salarial feminina nos principais polos tecnológicos da região sul, utilizando dados extraídos da Relação Anual de

$1 \quad$ As carreiras e ocupações que os órgãos do governo americano incluem no grupo STEM podem ser encontradas em: <http://nces.ed.gov/pubs2009/2009081.pdf $>$. STEM recebiam, em média, 26\% a mais do que os demais trabalhadores (BEEDE et al., 2011). 
Informações Sociais (RAIS)-MTE, para o ano de 2011. São selecionados os trabalhadores dos ramos das indústrias de transformação e de informação e comunicação, uma vez que são mais representativas das atividades típicas de polos tecnológicos. Dentre essas atividades, identificam-se quatro ocupações de análise de TI, que são consideradas em comparação com as demais ocupações pertencentes às atividades dos polos. Com isso, desenvolve-se uma análise robusta dos retornos às variáveis de produtividade - representadas pelo grau de escolaridade, idade e tempo no emprego - e da desvantagem salarial feminina.

O artigo está organizado em seis seções, incluindo esta introdução. A segunda seção traz um pano de fundo teórico-empírico do assunto tratado; a terceira descreve o método de seleção dos dados, bem como a metodologia da análise estatística da população considerada; a quarta apresenta a descrição não controlada do perfil da mão de obra atuante nos polos da região sul; a quinta seção discute os resultados da análise econométrica; e, por fim, a sexta traz as considerações finais da pesquisa.

\section{Aspectos Contextuais e Teóricos}

A entrada massiva da mulher na força produtiva começou na década de 1950, inicialmente em cargos e atividades de menor remuneração. À medida que as mulheres buscaram qualificação profissional, passaram a atuar de maneira mais generalizada no mercado de trabalho, em termos de faixas de rendimento. Isso tem contribuído para a redução do gap salarial entre os gêneros nas últimas duas décadas, embora tal redução seja modesta, se comparada ao avanço na escolarização das mulheres. ${ }^{3}$ Por exemplo, o estudo abrangente de Giuberti e Menezes Fillho (2005) aponta uma redução do gap salarial entre homens e mulheres, na década de 2000, tanto no Brasil, quanto nos Estados Unidos. A mesma tendência é mostrada para o Japão, Estados Unidos, Grã-Bretanha, Finlândia, França e Suécia, entre 1980 e 2010 (CLOSING..., 2011).

Outro aspecto das diferenças salariais é a variabilidade da desvantagem salarial feminina entre diferentes ocupações. O estudo de Giuberti e Menezes (2005), por exemplo, aponta que a média salarial feminina é maior que a masculina no setor brasileiro de construção civil. Porém, isso ocorre porque as poucas mulhe-

3 No Brasil, já em 2001, as mulheres representavam 56,3\% do total de alunos matriculados e 62,4\% do total de alunos que concluíram o ensino universitário (LETA, 2003). Com exceção dos países do sul da Ásia e da África sub-Sahara, no ano de 2014, mais da metade dos matriculados nos cursos de nível superior ao redor do mundo eram mulheres, notando que o conjunto dos países agrupados no sudeste asiático e Pacífico e o conjunto dos países árabes somente atingiram esse perfil de gênero universitário no início da década de 2010. (GENDER, 2015a). Em termos de mercado de trabalho, segundo, por exemplo, Caris e Hayo (2012), nos países árabes, em 2010, as mulheres representavam $18 \%$ da força de trabalho. 
res - provavelmente com formação em engenharia civil - que atuam nesse setor da atividade ocupam cargos com melhor qualificação do que a média masculina, já que a grande maioria da mão de obra empregada é masculina e com pouca qualificação.

Num outro extremo, estão os empregos pertencentes às áreas STEM, em que a grande maioria da mão de obra empregada possui elevado nível de qualificação e a participação feminina também é reduzida. ${ }^{4}$ Apesar de a participação das mulheres nessas áreas ser menor do que na média do mercado global, a desvantagem salarial feminina nos empregos STEM é menor do que na média do mercado. Em algumas carreiras, a desvantagem chega a ser invertida, com o salário médio dos homens ficando abaixo do das mulheres (GOLDBERG; HILL, 2007).

No que se segue, os empregos de analistas de TI, que são pertencentes às áreas STEM, são descritos e analisados no contexto dos polos tecnológicos da região sul brasileira. Considera-se tanto o aspecto do perfil de produtividade e composição de gênero dos trabalhadores, quanto o aspecto da vantagem salarial desses empregos e do grau de discriminação salarial feminina.

\section{Metodologia e Dados Utilizados}

A metodologia utilizada neste artigo possui seus fundamentos na teoria do capital humano, iniciada por Becker (1957). Essa teoria, em sua principal formulação, assume que a educação formal e o treinamento na empresa determinam as habilidades cognitivas do trabalhador, o que permite que se estabeleça uma relação tecnicamente direta entre as habilidades e a produtividade do trabalhador. Uma vez que, no modelo neoclássico, o salário deve ser equivalente à produtividade, estabelece-se, então, a conexão entre as habilidades e o salário.

A integração da teoria do capital humano com a análise estatística se viabiliza pelo desenvolvimento das funções mincerianas (MINCER, 1974; SCHULTZ, 1973), que forneceram um escopo básico para avaliação quantitativa do impacto dos atributos dos trabalhadores sobre seus salários. Tais atributos, como, por exemplo, grau de educação e experiência profissional, são supostamente determinantes da produtividade (ASHENFELTER; ROUSE, 1998; CARD; KRUEGER, 1992).

Já a abordagem da economia da discriminação identifica discriminação econômica no mercado de trabalho quando um grupo de indivíduos recebe salários

$4 \quad$ Embora não faça parte do escopo desse trabalho, vale apontar que o modo como as mulheres lidam com a tecnologia, ou mesmo o modo como fazem as escolhas da carreira profissional, tem sido abordado sob três perspectivas: a teoria essencialista (CECCO; ELIA, 1993; WAJCMAN, 1991), que privilegia os aspectos biológicos dos indivíduos; a teoria da construção social (MARINI, 1990; TRAUTH ET AL. 2005), que privilegia os aspectos sociais das atitudes em relação ao trabalho; e, mais recentemente, a teoria das diferenças individuais (TRAUTH, 2002; TRAUTH ET AL. 2004). 
diferentes ou tratamento diferenciado, apesar de possuírem as mesmas habilidades e produtividade - Loureiro (2003), por exemplo, apresenta uma resenha sobre a economia da discriminação.

A decomposição de Oaxaca - inicialmente abordada por Oaxaca (1973), e consolidada por Oaxaca e Ranson (1994, 1999) - é amplamente empregada na literatura sobre discriminação salarial por estimar as funções mincerianas para cada grupo separadamente, através da análise de regressão, e decompor o diferencial de média dos rendimentos. O modelo tradicional de decomposição de Oaxaca tornou-se tão rotineiro na literatura que Jann (2008), depois de apresentar em detalhes o método e expor algumas fragilidades, propôs e introduziu um novo comando de programação no software Stata ${ }^{\circledR}$ para decomposição de Blinder-Oaxaca. Ainda sobre essa metodologia, Gardeazabal e Ugidos (2004) já abordam o uso de variáveis dicotômicas para gênero como uma alternativa viável para se identificar discriminação de gênero nos salários.

\subsection{Modelo Econométrico}

O modelo econométrico utilizado neste trabalho é uma adaptação da decomposição de Oaxaca, em que se incluem, numa única função de salários, os atributos associados à produtividade e gênero do trabalhador. Além disso, uma variável dummy adicional de região permite considerar também as diferenças em termos dos estados do Paraná, Santa Catarina e Rio Grande do Sul.

A variável dependente é o log do salário-hora semanal do trabalhador. As variáveis explicativas, contidas na matriz $X$, são o gênero (masculino e feminino), a escolaridade (em intervalos), o tempo de emprego na empresa (medido em meses) e a idade dos trabalhadores (medida em anos). Além disso, inclui-se no modelo a idade ao quadrado para capturar o fato de que a idade é um atributo que apresenta retornos marginais decrescentes.

Assim, a análise econométrica se faz a partir da estimação do modelo semilogarítmico: ${ }^{5}$

$$
\operatorname{lny}_{\mathrm{i}}=\beta_{0}+\alpha_{0} \mathrm{D}_{\mathrm{j}}+\mathrm{x}_{\mathrm{i}} \beta+\alpha_{1}\left(\mathrm{D}_{\mathrm{j}} \mathrm{x}_{\mathrm{i}}\right)+\mathrm{u}_{\mathrm{i}}
$$

em que lny é o logaritmo do salário-hora de cada empregado (i) e o termo $\beta_{0}$ é uma variável latente que representa a heterogeneidade não observada no modelo.

5 Nota metodológica: nos modelos semilogarítmicos com variáveis dummies, Harvorsen e Palmquist (apud GUJARATI, 2000) sugerem que se tome o antilogaritmo do coeficiente binário estimado, se subtraia 1 e se multiplique o resultado por 100. Esse procedimento permite analisar o coeficiente também em termos percentuais, porém, nesse caso, o que se obtém não é a média, mas a mediana. 
O grau de escolaridade é dividido em quatro intervalos: ensino médio completo, superior incompleto, superior completo e pós-graduação. A categoria base de comparação é "homem com nível médio completo". Considera-se que existe discriminação salarial contra as mulheres quando a variável gênero é estatisticamente significativa para explicar o salário, já que o gênero não é atributo de produtividade.

As diferenças entre os três estados da região são capturadas através da matriz $D_{j}$ de variáveis dummy de interação multiplicativa e aditiva para cada variável de controle binária e para cada um dos estados (j). Assim, a matriz Dj permite diferenciar os coeficientes de inclinação das variáveis independentes com relação aos níveis de produtividade e gênero e distinguir entre os coeficientes de intercepto de cada estado.

Assume-se que o termo de erro $u_{i}$ é estocástico, não autocorrelacionado e com variância constante. Adota-se, ainda, a hipótese de ausência de correlação entre o erro e respectivo vetor explicativo $x_{i} E\left(u_{i} \mid x_{i}\right)=0$, considerando-se, portanto, que as variáveis explicativas são determinadas de maneira exógena no modelo. Testes adicionais de normalidade dos resíduos são feitos para garantir que os valores dos testes de significância individual e coletiva do modelo possam ser interpretados de maneira consistente. Adicionalmente, são testadas as hipóteses assumidas neste trabalho para se garantir que as estimativas dos parâmetros do modelo sejam eficientes e consistentes.

\subsection{Seleção dos Polos}

Em vários países, observa-se a constituição de polos da indústria de tecnologia, desde a formação do Vale do Silício, na Califórnia. No Brasil, essa tendência se intensificou durante a década de 2000. Nos três estados da região sul, encontram-se mais de 20 polos tecnológicos regionais, associados a diferentes áreas de atuação da economia local.

A Tabela 1 (ver Apêndice A) esclarece quais são os municípios que fazem parte da região metropolitana de cada polo tecnológico aqui considerado. Em geral, os polos regionais estão ligados à formação de parques tecnológicos, cujas empresas atuantes definem a principal área do polo. Assim, a Tabela 2 (ver Apêndice $\mathrm{A}$ ) resume as principais características dos polos selecionados em termos de seus parques tecnológicos.

No estado do Rio Grande do Sul, utilizou-se a classificação dos Conselhos de Desenvolvimento Regional. A Secretaria da Ciência, Inovação e Desenvolvimento Tecnológico do Rio Grande do Sul identifica 24 polos, sendo que 80\% de seus trabalhadores encontram-se nos três maiores, que são o metropolitano, o do Vale dos

Sinos e o da Serra. O polo metropolitano tem como cidade sede Porto Alegre e se 
destaca pelos clusters do Vale do Rio Pardo, associados à produção de fumo e ao setor de autopeças. O polo da Serra localiza-se na cidade de Caxias do Sul e está associado ao setor têxtil (CARVALHO; CHAVES, 2007). O polo do Vale do Rio dos Sinos situa-se na cidade de Canoas.

Em Santa Catarina, os polos ocorrem nas regiões de Blumenau - associado à indústria têxtil -, de Joinville - associado à indústria metal-mecânica - e na região da Grande Florianópolis, associado à indústria de software. Foi utilizado o critério das Secretarias de Estado de Desenvolvimento Regional (SDR) para se definir a região metropolitana de cada polo.

No Paraná, foram identificados os polos de Curitiba, Londrina, Maringá, Oeste e Sudoeste. Tanto a identificação dos polos regionais, quanto a dos municípios que fazem parte da região seguem o trabalho do Sebrae, Panorama Setorial de Tecnologia da Informação, publicado por Pereira (2010). Os dois maiores polos são o da região metropolitana de Curitiba, voltado ao setor de telecomunicações, e o da região de Maringá, voltado ao setor de confecções.

\subsection{Base de Dados e Seleção das Atividades Industriais nos Polos}

Os dados deste artigo foram obtidos da RAIS para o ano de 2011. A RAIS publica as informações organizadas de acordo com a Classificação Nacional de Atividades Econômicas (CNAE), elaborada pelo IBGE, que organiza hierarquicamente as atividades em 21 seções, 87 divisões, 285 grupos, 673 classes e 1.301 subclasses. Como as cidades polos regionais englobam diversas atividades, buscou-se enfocar aquelas que caracterizam o setor da indústria de transformação. Além desse, considerou-se também o setor de informação e comunicação, porque é onde se inserem as várias atividades associadas à prestação de serviços, inclusive os serviços de tecnologia da informação.

Quadro 1 - Classificação CNAE 2.0 e as atividades selecionadas

Seção C: indústria de transformação (subdividida em 34 divisões).

Divisão 26: fabricação de equipamentos de informática, produtos eletrônicos e ópticos (subdividida em oito grupos de 261 a 268).

Grupo 263: fabricação de equipamentos de comunicação (subdividida em duas classes).

Classe 263-1: fabricação de equipamentos transmissores de comunicação.
Seção J: informação e comunicação (subdividida em seis divisões).

Divisão 62: atividades dos serviços de tecnologia da informação (contém um grupo).

Grupo 620: atividades dos serviços de tecnologia da informação (subdividida em cinco classes).

Classe 6204-0: consultoria em serviços de tecnologia da informação. 
conclusão.

Subclasse 263-1/00: fabricação de equipamentos transmissores de comunicação, peças e acessórios.
Subclasse 6204-0/00: consultoria em serviços de tecnologia da informação.

Fonte: Elaboração própria a partir de IBGE (2013).

Assim, para o presente artigo, selecionaram-se os trabalhadores registrados na divisão 26 da seção $\mathrm{C}$ e na divisão 62 da seção $\mathrm{J}$ da classificação CNAE. Em cada uma dessas divisões, foram selecionados todos os grupos e, dentro deles, todas as classes e subclasses. O Quadro 1 exemplifica um ramo de cada uma dessas duas seções e respectivas divisões selecionadas.

\section{Descrição dos Dados: Perfil de Produtividade e Gênero dos Empregados}

Esta seção descreve o perfil dos trabalhadores dos polos tecnológicos e da área de Análise de TI. Cada empregado é registrado pelo empregador de acordo com a atividade a que pertence a ocupação exercida. Como cada polo possui algumas características próprias, o número de ocupações encontradas difere entre os estados, porém muitas ocupações são comuns aos três estados. Assim, tomados os dados em conjunto para a região sul, totalizam-se 726 ocupações, sendo que quatro delas pertencem à atividade de análise de TI: analista de desenvolvimento de sistemas, analista de redes e de comunicação de dados, analista de suporte computacional e analista de sistemas de automação. Essas ocupações de analista de TI são comuns a todos os polos regionais e constituem relativamente alta proporção de trabalhadores em cada polo.

Quadro 2 - Total de empregados nos polos tecnológicos em cada estado

\begin{tabular}{|c|c|c|c|c|c|c|}
\hline \multirow{2}{*}{$\begin{array}{c}\text { Trabalha- } \\
\text { dores }\end{array}$} & \multicolumn{2}{|c|}{ Santa Catarina } & \multicolumn{2}{|c|}{ Paraná } & \multicolumn{2}{|c|}{ Rio Grande do Sul } \\
\hline & $\begin{array}{c}369 \\
\text { ocupações }\end{array}$ & $\begin{array}{c}\text { Analistas } \\
\text { de TI }\end{array}$ & $\begin{array}{c}531 \\
\text { ocupações }\end{array}$ & $\begin{array}{c}\text { Analistas } \\
\text { de TI }\end{array}$ & $\begin{array}{c}513 \\
\text { ocupações }\end{array}$ & $\begin{array}{c}\text { Analistas } \\
\text { de TI }\end{array}$ \\
\hline Total & 13.321 & 3.414 & 22.016 & 2.995 & 23.812 & 3.251 \\
\hline $\begin{array}{l}\text { Percen- } \\
\text { tagem } \\
\text { feminina }\end{array}$ & $33,66 \%$ & $24,4 \%$ & $37,18 \%$ & $18,7 \%$ & 38,95 & $20,6 \%$ \\
\hline
\end{tabular}

Fonte: Elaboração própria a partir de dados de Brasil (2011).

Como mostrado no Quadro 2, nos três estados, a participação das mulheres como analistas de TI é menor do que nas demais ocupações selecionadas para os polos. No Paraná, por exemplo, as mulheres representam 37,18\% dos trabalhadores das regiões dos polos, mas são apenas 18,7\% dos analistas de TI. Essa sub-representação feminina nas carreiras de analista de TI tem sido constatada nas 
economias americana, canadense, australiana e europeia (TRAUTH e QUESENBERY, 2007). A Figura 1 ilustra a média salarial em cada um dos estados da região.

Figura 1-Salário médio por hora semanal*

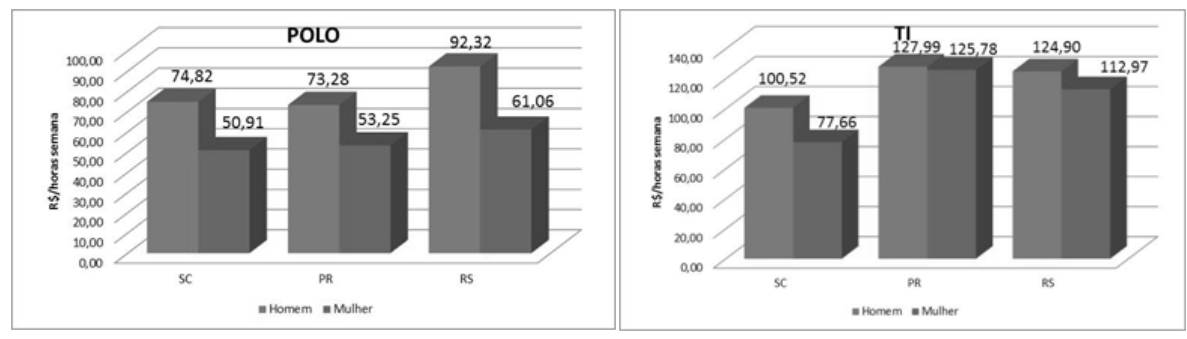

Fonte: Elaboração própria a partir de dados de Brasil (2011).

Nota: *O valor do salário médio utilizado no estudo foi obtido dividindo-se o salário médio dos trabalhadores pelo número de horas de trabalho semanais.

Observam-se três tendências comuns aos três estados. A primeira é que o salário médio dos analistas de TI é maior do que a média do grupo mais abrangente de ocupações, evidenciando o "prêmio" pela carreira de TI. A segunda é a desvantagem salarial das mulheres tanto em termos do conjunto amplo de ocupações, quanto em termos das analistas de TI. A terceira é que essa desvantagem feminina é menor entre os profissionais de análise de TI do que para a média das demais ocupações.

No estado de Santa Catarina, o salário médio das mulheres é cerca de $32 \%$ menor que o dos homens, mas a média salarial das mulheres que atuam como analistas de TI é 22,75\% menor que a dos homens. No Paraná, o salário médio das mulheres é $27,3 \%$ menor do que a dos homens, mas, para as mulheres que atuam como analistas de TI, essa desvantagem salarial quase desaparece, ficando seu salário apenas 1,73\% menor do que o dos homens. Nos polos tecnológicos regionais do Rio Grande do Sul, o salário-hora das mulheres é, em média, 34\% menor do que o dos homens, mas essa desvantagem feminina é muito menor para as analistas de TI, que recebem em média 9,5\% a menos do que os homens.

As Figuras 2, 3 e 4 apresentam o perfil dos trabalhadores dos polos tecnológicos em termos das variáveis-atributos a serem consideradas como explicativas do processo de formação salarial. De acordo com a teoria do capital humano, tanto a idade, quanto o tempo no emprego estão associados à experiência do trabalhador na atividade que desempenha. 
Figura 2 - Idade média por estado em 2011
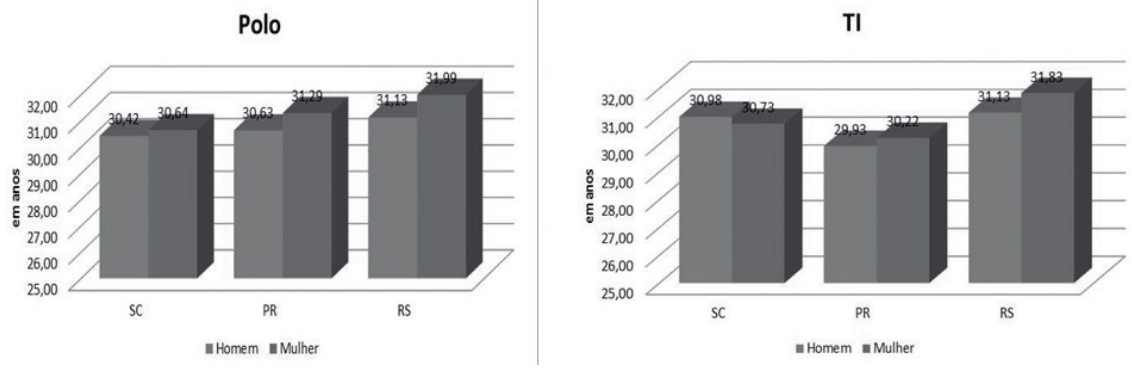

Fonte: Elaboração própria a partir de dados de Brasil (2011).

A Figura 2 mostra a idade média em cada estado para o conjunto de todas as ocupações selecionadas e para as ocupações de análise de TI. No estado de Santa Catarina Paraná, os trabalhadores do polo apresentam a menor média de idade e, no Rio Grande do Sul, a maior média. Já para o conjunto específico dos analistas de TI, a menor média de idade ocorre no Paraná, mas o Rio Grande do Sul continua a apresentar a maior média de idade. Com exceção das analistas de TI de Santa Catarina, as mulheres possuem maior média de idade do que os homens. Observa-se, ainda, que não existe aparentemente uma diferença de idade significativa entre a média dos trabalhadores do conjunto amplo de ocupações e a do conjunto de análise de TI.

$\mathrm{Na}$ associação entre o tempo no emprego e o salário do trabalhador, em geral, quanto maior o tempo em que se exerce uma ocupação, maior a habilidade e maior deve ser o salário. Com base na Figura 3, é possível perceber que, para o conjunto amplo de ocupações dos polos, o tempo médio de emprego das mulheres é superior ao tempo médio dos homens. Os trabalhadores dos polos regionais do Rio Grande do Sul têm, em média, mais tempo de emprego do que os dos demais estados, enquanto os do Paraná, em média, têm menor tempo no emprego.

Figura 3 - Tempo de emprego médio (em meses)
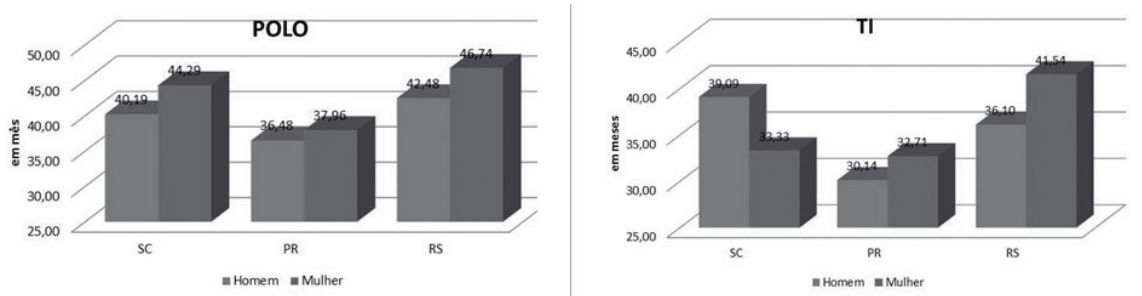

Fonte: Elaboração própria a partir de dados de Brasil (2011). 
Ao se comparar as ocupações específicas de análise de TI, nota-se que, em Santa Catarina, as mulheres têm em média menor tempo no emprego do que os homens. Já o oposto é observado nos outros dois estados: os empregados com maior média de tempo no emprego estão no Rio Grande do Sul, enquanto que, no Paraná, estão os analistas de TI com menor tempo no emprego.

Figura 4 - Perfil de escolaridade dos trabalhadores

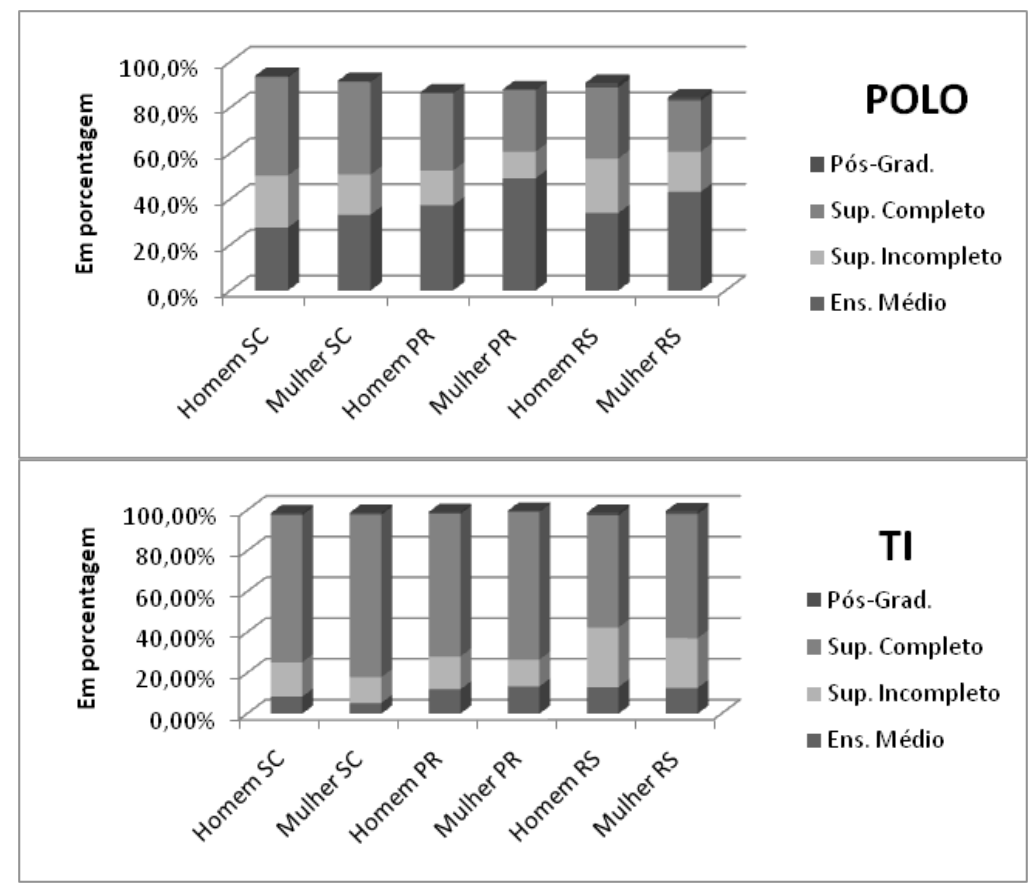

Fonte: Elaboração própria a partir de dados de Brasil (2011).

A Figura 4 apresenta o perfil educacional dos trabalhadores que atuam nas atividades selecionadas dos polos regionais de cada estado. Os polos de Santa Catarina apresentam o maior nível educacional da região sul, tanto em termos do total de ocupações selecionadas, quanto em termos dos analistas de TI.

Para o conjunto amplo de ocupações, observa-se que, nos três estados, os homens possuem escolaridade média acima da das mulheres. Em Santa Catarina, respectivamente $65,7 \%$ e $58,1 \%$ dos homens e das mulheres possuem níveis superior completo e incompleto. No Paraná, essas proporções são respectivamente 49,0\% e 38,6\% e, no Rio Grande do Sul, 55,0\% e 39,9\%, respectivamente.

Já para os analistas de TI, nos três estados as mulheres têm nível de escolaridade mais alto do que o dos homens. Nos polos de Santa Catarina, por exemplo, $79,8 \%$ das analistas de TI possuem nível superior completo, enquanto que, para os 
homens, essa proporção é 72,3\%. Esse perfil de gênero-escolaridade se assemelha ao encontrado nos Estados Unidos. Lá, as mulheres que atuam nos empregos das áreas STEM, entre os quais estão os analistas de TI, possuem maior grau de escolaridade do que os colegas do sexo masculino, de acordo, por exemplo, com Langdon et al. (2011).

\section{Resultados da Análise Estatística}

Nessa seção, são apresentados os resultados da estimação do modelo da equação 1 (ver seção 3.1) de acordo com o método dos mínimos quadrados ordinários (MQO), estimado de maneira robusta corrigindo-se a heterocedasticidade pela matriz de White. Os resultados da análise de regressão são resumidos nas Tabelas 3 e 4, do Apêndice B, e são aqui interpretados com o objetivo de se comparar os analistas de TI com o grupo mais amplo de ocupações, em termos de discriminação salarial feminina e de retorno às variáveis de produtividade.

Todas as variáveis explicativas apresentam coeficientes estatisticamente significativos ao nível de 1\% de significância. As seis primeiras variáveis, na Tabela 3, são proxies que representam atributos determinantes da produtividade. Já o gênero do trabalhador, quando estatisticamente significativo para se explicar o salário, indica a existência de discriminação salarial. O modelo econométrico permite que se mantenham constantes os parâmetros relativos às demais variáveis explicativas e que se modifiquem apenas aqueles associados ao gênero do trabalhador. No que se segue, os resultados da Tabela 3 são ilustrados pelas Figuras 5 a 8.

\subsection{Estimando os Retornos da ldade, Escolaridade e Tempo no Emprego}

Com o objetivo de auxiliar a análise e interpretação dos resultados do modelo de regressão, os coeficientes estimados foram transformados para serem apresentados na forma gráfica. Assim, as Figuras 5 a 8 ilustram o impacto de cada variável explicativa na estrutura salarial da população em estudo. Trata-se da variação salarial, em termos percentuais, resultante da mudança marginal na variável-atributo, mantendo-se as demais variáveis constantes.

A Figura 5 ilustra o impacto da idade do trabalhador sobre seu salário médio. As curvas representam o aumento percentual no salário em relação à categoria tomada como referência, que é a do trabalhador do sexo masculino com idade de 18 anos na região sul. Assim, ao longo de cada curva, tem-se o aumento percentual no salário em resposta ao aumento da idade. Além disso, as distâncias entre as curvas indicam as diferenças na resposta do salário médio ao avanço da idade entre os estados quando comparados com a média da região sul. 
Figura 5 - Retornos da variável idade: resultados ajustados pela regressão
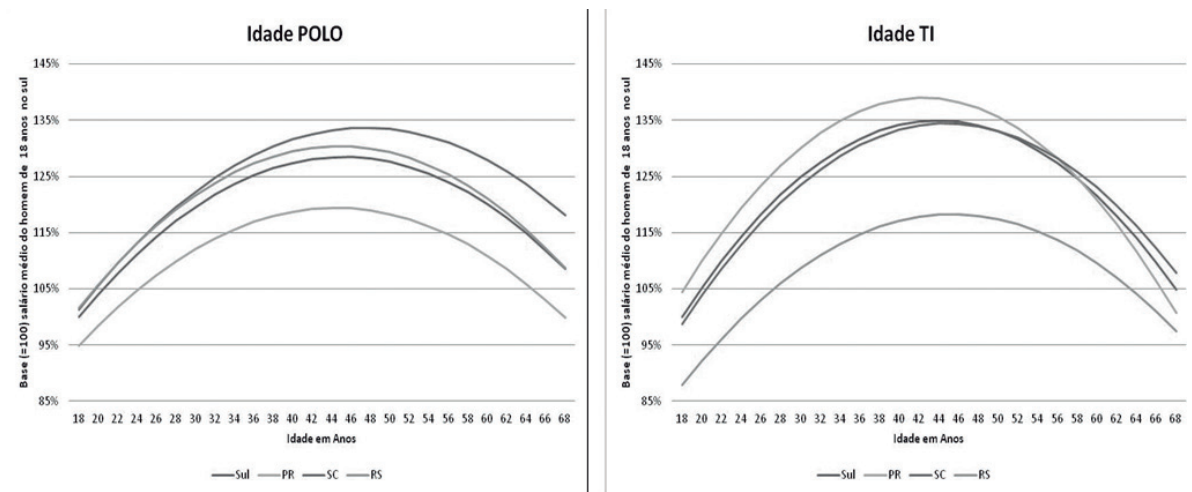

Fonte: Elaboração própria a partir de dados de Brasil (2011).

A convexidade das curvas de idade-rendimento, apresentada pelos três estados, é uma ilustração da formulação de Mincer (1974) com base em Becker (1993). ${ }^{6}$ Parte-se do pressuposto de que as pessoas concentram seus investimentos em capacitação profissional e educação formal no início da carreira, alocando, assim, seu tempo entre trabalho e profissionalização. Nessa fase, os rendimentos aumentam rapidamente ao longo dos anos. Ao se aproximar da idade de aposentadoria, os rendimentos passam a declinar com o avanço da idade.

Para o conjunto abrangente de ocupações nos polos, no estado de Santa Catarina o ponto de inflexão dos salários ocorre aproximadamente aos 47,5 anos e no Paraná e no Rio Grande do Sul, aos 44,4 e 44,7 anos, respectivamente. O menor retorno salarial à idade é observado no Paraná e o maior retorno, em Santa Catarina. O estado do Rio Grande do Sul fica numa posição entre os outros dois, mas acima da média da região sul.

Já para os analistas de TI, em Santa Catarina, os retornos salariais devidos à idade são menores do que no caso das demais ocupações dos polos. O gráfico da direita na Figura 5 indica que o Paraná apresenta o maior retorno à idade, enquanto o Rio Grande do Sul, o menor retorno à idade. Além disso, diferentemente dos outros dois estados, no Rio Grande do Sul a idade de inflexão dos salários dos analistas de TI é superior à média do polo, ficando aproximadamente em 45,4 anos.

A média de idade dos analistas de TI é a menor no estado do Paraná, enquanto a maior média de idade é observada no Rio Grande do Sul (conforme ilustra a Figura 2, na seção 4). Como no Rio Grande do Sul os polos tecnológicos estão relacionados a atividades mais tradicionais e com maior média de idade dos

6 Para uma resenha do desenvolvimento da metodologia empírica dessa teoria, na forma das funções mincerianas, ver, por exemplo, Heckman, Lochner e Todd (2003) e Willis (1986). 
trabalhadores, pode-se conjecturar, com base na teoria do capital humano, que nesses polos se invista menos em capacitação no início da carreira.

Para a variável explicativa "tempo no emprego", a Figura 6 ilustra a interpretação geométrica dos resultados dos coeficientes da regressão, indicando o aumento percentual no salário devido ao acréscimo de um mês no tempo de emprego do trabalhador. A categoria tomada como base é o grupo de trabalhadores com um mês de registro no emprego para os dados dos três estados da região sul conjuntamente. No quadro à esquerda são usados os dados de todo o polo e o no quadro à direita, apenas os analistas de TI. Nos dois casos, o salário aumenta linearmente à medida que aumenta o tempo no emprego em todos os estados.

Figura 6 - Retornos do tempo no emprego: resultados ajustados pela regressão


Fonte: Elaboração própria a partir de dados de Brasil (2011).

Assim, as curvas dos gráficos da Figura 6 ilustram que tanto para o conjunto amplo de ocupações, quanto para os analistas de TI a média salarial dos trabalhadores aumenta mais rapidamente com o tempo no emprego no estado do Paraná, mas esse aumento é ainda mais rápido para os analistas de TI. Já Santa Catarina apresenta a menor resposta salarial ao aumento do tempo no emprego, e essa característica é ainda mais acentuada para os analistas de TI.

De acordo com o resultado da Tabela 3, para o conjunto amplo de ocupações, o coeficiente da variável "tempo no emprego" para Santa Catarina é de $0,325 \%$, o que significa que cada mês adicional de tempo no emprego gera um aumento de $0,325 \%$ no salário médio.

Para o estado do Paraná, o coeficiente estimado indicou que, em média, os profissionais do polo com um mês a mais de emprego recebem um salário 0,578\% maior. No Rio Grande do Sul, em média, para cada mês a mais trabalhando no polo tecnológico, os trabalhadores ganham $0,439 \%$. Como a categoria base é a região sul, as curvas da Figura 6 indicam que o Paraná apresenta a maior média salarial, enquanto Santa Catarina, a menor média. 
Para os analistas de TI, no estado de Santa Catarina cada mês a mais de trabalho implica, em média, 0,271\% a mais no salário, o que significa que o retorno ao tempo no emprego é menor para os analistas de TI do que no conjunto abrangente de ocupações. No Paraná, observa-se que, para cada mês adicional de trabalho, o salário sofre um incremento de $0,8 \%$ e no Rio Grande do Sul, um aumento de $0,498 \%$ no salário.

Quanto à variável escolaridade, a categoria base de comparação é a dos funcionários com ensino médio. Assim, os coeficientes da regressão fornecem a estimativa do aumento salarial quando se passa desse nível de escolaridade a outro superior. Os gráficos da Figura 7 apresentam uma ilustração geométrica dessas estimativas. $^{7}$

Figura 7 - Retornos da variável escolaridade: resultados ajustados pela regressão
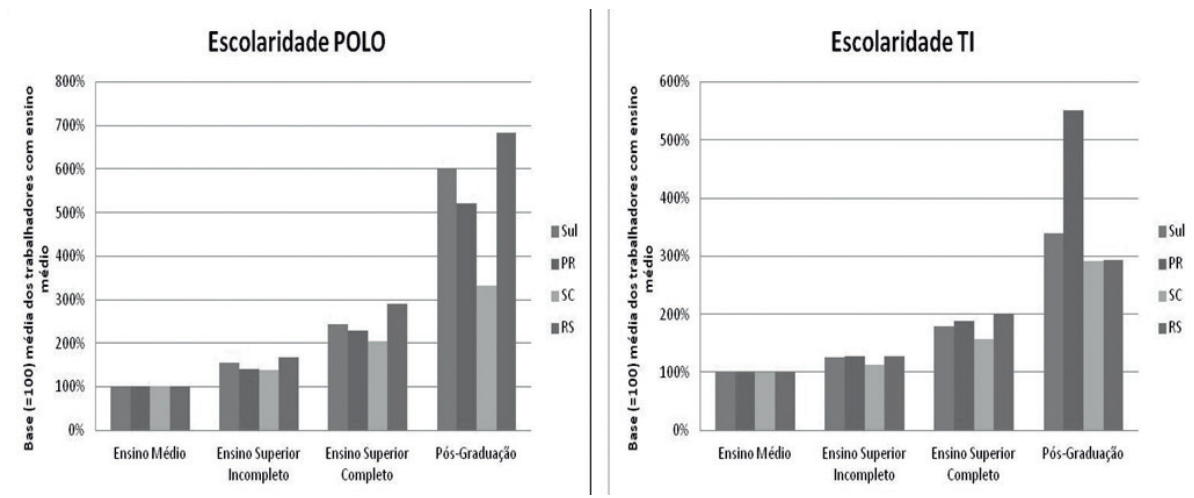

Fonte: Elaboração própria a partir de dados de Brasil (2011).

Para o conjunto amplo de ocupações, a Tabela B.3, do Apêndice B, indica que, nos polos de Santa Catarina, os salários aumentam substancialmente com a escolaridade, podendo chegar a uma diferença de $231,28 \%$ a mais para um pós-graduado. A média do salário de um homem com ensino superior incompleto é $37,41 \%$ maior do que a de um homem com apenas ensino médio completo. Já a média do salário de um homem com nível superior completo chega a ser 104,78\% maior. Para os estados do Paraná e do Rio Grande do Sul, as diferenças salariais

7 Cabe observar que, argumenta-se, por vezes, que o grau de escolaridade é uma variável endógena na função salarial, isto é, pode haver uma simultaneidade de determinação salário-escolaridade, sendo ambas variáveis influenciadas por fatores omitidos no modelo, tais como habilidades, motivação, background familiar - ver, por exemplo, Card (2001) para uma discussão. A endogeneidade de uma das variáveis explicativas- no caso, a escolaridade, invalida a hipótese de que os erros são não correlacionados, o que implica que a estimativa do impacto da escolaridade sobre a média salarial não é consistente. Entretanto, no presente estudo, a análise da relação entre a variável escolaridade e o termo de erro do modelo não produziu uma relação estatisticamente significativa. 
são ainda maiores, à medida que se comparam funcionários com níveis de escolaridade mais elevados.

No Paraná, funcionários com ensino superior incompleto ganham, em média, 40,2\% a mais do que aqueles com apenas ensino médio. $\mathrm{O}$ ensino superior completo e a pós-graduação no Paraná garantem aumentos na média salarial de $128,37 \%$ e $420,88 \%$, respectivamente. No estado do Rio Grande do Sul, o acréscimo no rendimento devido ao aumento da escolaridade é ainda maior. Em comparação com um funcionário de ensino médio, os salários dos trabalhadores com ensino superior incompleto, completo e pós-graduação são, em média, 68,55\%, $190,70 \%$ e $582,32 \%$, respectivamente, maiores.

Já para os analistas de TI, com exceção do nível de pós-graduação no Paraná, observa-se que a recompensa salarial pelo aumento de escolaridade é proporcionalmente menor do que para o grupo amplo de ocupações. Em Santa Catarina, em relação ao nível de ensino médio, os graus de ensino superior incompleto, superior completo e pós-graduação geram um aumento de, respectivamente, $13,05 \%, 56,62 \%$ e $191,77 \%$ na média salarial. No Paraná, os analistas com nível superior incompleto ganham $26,95 \%$ a mais do que aqueles com nível médio, e aqueles com nível superior completo e pós-graduação recebem, respectivamente, 89,05\% e 451,54\% a mais. Já no Rio Grande do Sul, a mudança no nível de escolaridade dos analistas de TI proporciona o aumento de $27,24 \%$ para ensino superior incompleto, 100,46\% para ensino superior completo e 192,90\% para nível de pós-graduação. Portanto, o Paraná é o estado onde mais se recompensa o avanço do nível educacional até ao de nível de pós-graduação entre os analistas de TI.

\subsection{Discriminação Salarial Feminina}

Uma vez analisados os impactos dos atributos de produtividade do trabalhador sobre seu salário, resta considerar os resultados das estimativas para o gênero do trabalhador. Os gráficos da Figura 8 são gerados a partir da última linha da Tabela 3, no Apêndice B, de coeficientes estimados. 
Figura 8 - Salário médio relativo (feminino/masculino): resultados ajustados pela regressão
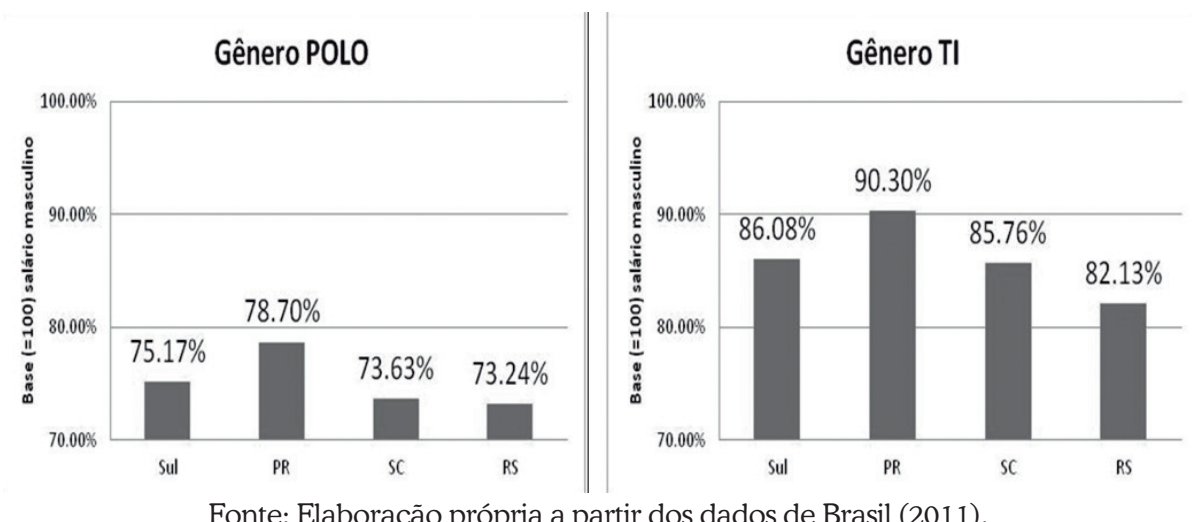

Fonte: Elaboração própria a partir dos dados de Brasil (2011).

É importante destacar que a diferença estimada entre os salários dos homens e das mulheres mostrou-se estatisticamente significativa para cada um dos estados da região - inclusive nos testes de contribuição marginal. Esse resultado pode ser interpretado como indicativo de que nos três estados existe discriminação salarial feminina, uma vez que, controlando os demais atributos associados à produtividade, os salários ainda são influenciados pelo gênero do trabalhador.

Para o conjunto amplo de ocupações dos polos, em média, na região sul, o salário médio das mulheres representa 75,17\% do dos salários dos homens. Já para as analistas de TI, essa proporção sobe para $86,08 \%$. Isso significa que a desvantagem salarial das mulheres nos polos é de $24,8 \%$, mas, para as analistas de TI, essa desvantagem se reduz para $13,92 \%$.

No Rio Grande do Sul, o salário médio das mulheres representa 73\% do salário médio dos homens no polo completo e $82 \%$ dos analistas de TI. Assim, em média, para cada $R \$ 1,00$ ganho por um homem empregado nos polos do Rio Grande do Sul, uma mulher ganha $R \$ 0,73$, e para cada $R \$ 1$ ganho pelo analista de TI, uma mulher ganha $\mathrm{R} \$ 0,82$. Similarmente, em Santa Catarina as mulheres ganham $\mathrm{R} \$ 0,73$ e $\mathrm{R} \$ 0,86$ para cada $\mathrm{R} \$ 1$ ganho por um homem, respectivamente, no polo e nas ocupações de análise de TI. Já no Paraná, onde se identifica o menor gap salarial de gênero, nos polos completos o salário médio feminino representa 78,7\% do masculino e $90,3 \%$ do dos analistas de TI. Assim, as mulheres ganham cerca de $21 \%$ a menos do que os homens nos polos, mas as que atuam como analistas de TI têm sua desvantagem reduzida para cerca de 10\%. Assim, os resultados da regressão indicam que, tanto para o conjunto mais amplo de ocupações, quando 
para as ocupações de análise de TI, o maior gap salarial está no Rio Grande do Sul, enquanto o menor gap, no Paraná. ${ }^{8}$

Na próxima seção, avalia-se em que medida essas diferenças entre os estados pode ser considerada estatisticamente significativa.

\subsection{Análise Cruzada entre os Estados}

Além dos atributos e da ocupação, a região onde o vive o trabalhador também pode figurar como uma variável que contribui para a formação salarial. No modelo da equação 1 (ver seção 3.1), a matriz $D_{i}$ contém as variáveis dummies de interação multiplicativa e permite que se utilize a região em que o trabalhador vive como uma variável dummy adicional. Com isso, pode-se avaliar se a média salarial de um grupo varia quando se muda de um estado a outro, mantendo-se os seus atributos constantes. Além disso, pode-se também determinar se os estados da região diferem em termos dos impactos das variáveis de produtividade e gênero sobre a média salarial. A análise estatística foi feita em termos de um nível de significância de 1\% (os resultados da regressão são expostos na Tabela B.2 do Apêndice B).

Na Figura 5 são ilustrados os retornos médios à idade do trabalhador em cada estado. A análise estatística controlada resulta que não se pode considerar que haja diferença entre os estados do Rio Grande do Sul e Santa Catarina para os dados do conjunto amplo de ocupações. Já entre Rio Grande do Sul e Paraná, e entre Paraná e Santa Catarina, a diferença de retornos salariais ilustrada na Figura 5 é estatisticamente significativa para pequenas diferenças de idade.

Para o grupo de analistas de TI, a descrição dos dados sobre os retornos à idade é apresentada no quadro do lado direito da Figura 5. Observa-se que os maiores retornos à idade ocorrem no estado do Paraná, seguido de Santa Catarina. Porém, a análise econométrica resulta que a diferença entre o Paraná e Santa Catarina não é estatisticamente significativa, indicando que os retornos salariais associados à idade nesses dois estados são equivalentes. Já a comparação entre o Rio Grande do Sul e os outros dois estados, ao contrário do observado para os dados dos polos completos, há uma diferença estatisticamente significativa no retorno salarial associado à idade, o que sugere que o analista de TI que atua no Rio Grande do Sul tem um menor retorno quanto à idade.

A Figura 6 ilustra o retorno salarial da variável explicativa "tempo no emprego”. As diferenças entre os estados são estatisticamente significativas, para a comparação entre dois estados quaisquer. Pode-se, então, dizer que o maior impacto

$8 \quad$ Não é possível considerar que o prêmio de TI seja estimado como a diferença entre as distâncias salariais feminina e masculina porque os analistas de TI estão incluídos no grupo amplo de ocupações do polo. 
do tempo no emprego como variável explicativa do salário ocorre no Paraná, seguido do Rio Grande do Sul e depois de Santa Catarina. Esse é o caso tanto dos empregados no conjunto amplo de ocupações, quanto dos analistas de TI.

Quanto aos retornos médios ao avanço da escolaridade, para o conjunto amplo de ocupações, tomando-se como base os trabalhadores com ensino médio, o modelo econométrico resulta que o único grau de escolaridade cujos retornos salariais não apresentam diferenças significativas é o nível superior incompleto, quando se comparam os estados do Paraná e de Santa Catarina. Então, pode-se dizer que os maiores retornos à educação, para o conjunto amplo de ocupações, são observados no estado do Rio Grande do Sul e o segundo maior, no Paraná.

Já para os analistas de TI, tomando novamente como base os trabalhadores com ensino médio, os resultados da análise estatística apontam que não se pode dizer que haja diferença de retorno salarial entre os estados de Santa Catarina e Rio Grande do Sul para a escolaridade em nível de pós-graduação. Portanto, a obtenção de uma pós-graduação, para o analista de TI, gera o mesmo impacto salarial no Rio Grande do Sul ou em Santa Catarina. Já os níveis de escolaridade de ensino superior incompleto e completo têm o mesmo impacto sobre o salário nos estados do Rio Grande do Sul e Paraná. Todos os demais níveis de escolaridade mostram uma diferença estatisticamente significativa em termos de retorno salarial quando se comparam os estados dois a dois, sendo que os menores retornos à educação ocorrem em Santa Catarina em todos os níveis de escolaridade. Os maiores retornos à pós-graduação, para os analistas de TI, são observados no Paraná.

Por fim, em termos de discriminação salarial por gênero, nos três estados existe uma desvantagem salarial feminina, mesmo controlando as variáveis de produtividade, sendo essa desvantagem menor no Paraná, quando comparado ao Rio Grande do Sul. As mulheres que trabalham nos polos tecnológicos do Rio Grande do Sul recebem 6,93\% a menos do que aquelas que atuam nos polos do Paraná. Já em Santa Catarina, as mulheres ganham 6,88\% ${ }^{9}$ a menos do que no Paraná, e a divergência entre a desvantagem feminina nos estados de Santa Catarina e Rio Grande do Sul não chega a ser estatisticamente significativa, podendo-se dizer que o grau de discriminação salarial é o mesmo no Rio Grande do Sul e em Santa Catarina.

Considerando-se apenas os analistas de TI, os resultados da regressão sugerem que o Rio Grande do Sul apresenta a maior desvantagem feminina, enquanto o Paraná possui a menor desvantagem, sendo que nesses estados o salário médio das mulheres corresponde, respectivamente, a $82 \%$ e 90,5\% do salário médio dos

9 Nota metodológica: para se obter maior precisão estatística e matemática, esses valores correspondem ao antilog-1 dos coeficientes da regressão transcritos no Apêndice B, Tabela 4. No entanto, eles são levemente diferentes dos valores apresentados na Figura 8 por causa da transformação na escala logarítmica. 
homens. Mesmo mantendo as demais variáveis explicativas constantes, as mulheres que trabalham nos polos tecnológicos no Rio Grande do Sul ganham, em média, 9,05\% a menos do que as que trabalham nos polos tecnológicos do Paraná. Já o estado de Santa Catarina não apresenta diferença estatisticamente significativa, em termos de desvantagem feminina, em relação aos outros dois estados. Assim, pode-se dizer que o mercado de trabalho dos polos tecnológicos de Santa Catarina impõe o mesmo grau de discriminação salarial às analistas de TI que os polos tecnológicos dos dois estados vizinhos.

\subsection{Discussão dos Resultados}

O perfil de gênero da força de trabalho nos polos regionais descritos na seção três se assemelha às características observadas internacionalmente. Em especial, destaca-se a sub-representação feminina nos empregos de análise de TI, que, por sua vez, são empregos pertencentes ao grupo STEM e cuja formação acadêmica requerida é nas carreiras de ciências da computação e engenharias. Nos países da OCDE, as mulheres dominam as áreas de educação, saúde, artes e humanidades, enquanto os homens são grande maioria nas áreas de computação, engenharias e física. (GENDER..., 2015b). No mercado de trabalho americano, em 2009, apenas $24 \%$ dos postos de trabalho no conjunto das carreiras STEM eram ocupados pelas mulheres, embora $48 \%$ da força de trabalho da economia já fosse composta por mulheres (BEEDE, 2011; ANITA BORG INSTITUTE, 2005).

O perfil de gênero observado nos locais de trabalho reflete o mesmo perfil da população universitária, que, por sua vez, reflete as escolhas que as mulheres fazem ao iniciar um curso superior. Em termos da região sul brasileira, uma ilustração da composição de gênero dos cursos universitários na região da Grande Florianópolis, entre 2007 e 2009, é fornecida por Bonini, Cemin e Menezes (2011). As mulheres eram $54,74 \%$ dos ingressantes e $57 \%$ dos concluintes nos cursos de graduação em geral, mas apenas $9 \%$ dos ingressantes e 12\% dos concluintes nos cursos de graduação em Ciências da Computação e Sistemas de Informação. As concluintes nos cursos de graduação em Sistemas de Informação e Engenharia Mecânica eram, respectivamente, 13\% e 5\% do total.

Para a economia americana, por exemplo, Dey e Hill (2007) apresentam uma descrição abrangente do perfil de gênero dos cursos de formação em nível superior e dos empregados em termos de áreas do conhecimento, bem como do gap salarial de gênero através das diferentes ocupações. As mulheres têm reduzida participação nos cursos de formação e empregos nas áreas de ciências da computação e engenharias e predominam nas carreiras de educação. No entanto, a média salarial feminina, em 2001, era 92\% da média masculina dentre os profissionais 
com formação e atuação em ciências da computação e, nas engenharias, a média salarial feminina era $5 \%$ maior do que a masculina.

No caso específico dos analistas de TI, cuja formação requerida é primordialmente em sistemas de informação, ciência da computação ou engenharia da computação, parece natural que a participação feminina nos locais de trabalho seja reduzida. Porém, as mulheres que desafiam esse território masculino conseguem estreitar a desvantagem salarial em relação aos homens. A Figura 8 na seção anterior ilustra essa menor desvantagem salarial para o conjunto de analistas de TI, em comparação ao grupo mais amplo de ocupações nos polos tecnológicos da região brasileira. A questão que se coloca é o porquê da maior homogeneidade salarial entre homens e mulheres em empregos, tais como analistas de TI.

Nesse contexto, vale observar que as técnicas econométricas aqui empregadas se fundamentam na teoria do capital humano, para a qual as variáveis explicativas incluídas no modelo supostamente determinam a produtividade do trabalhador e, portanto, o salário. Porém, não se pode descartar a existência das variáveis omitidas, que podem contribuir para explicar as médias salariais entre os grupos.

Pode-se conjecturar que as mulheres detenham algum atributo que lhes garanta vantagem comparativa em relação aos homens no exercício dos empregos de análise de TI. Porém, não é apenas nos empregos de analistas de TI que a desvantagem salarial feminina é reduzida. De fato, no conjunto dos empregos STEM, nos Estados Unidos, por exemplo, as mulheres possuem menor desvantagem em relação aos homens, com uma média salarial 14\% menor do que a masculina, enquanto que nos empregos não STEM, a média salarial feminina era $21 \%$ menor do que a masculina em 2010. Essa redução da desvantagem feminina nos empregos STEM decorre do fato de que as mulheres auferem um prêmio salarial STEM superior ao prêmio masculino.

Em termos das comparações entre os estados da região sul, os principais resultados qualitativos da análise vão todos na mesma direção, com pequenas diferenças entre os estados, em termos quantitativos. As diferenças encontradas podem ter origem nas especificidades das economias regionais onde se encontram os polos tecnológicos analisados. No Rio Grande do Sul, por exemplo, os principais polos tecnológicos estão associados a atividades mais tradicionais, sendo os maiores os polos das regiões de Porto Alegre e Canoas, este último vinculado à atividade de fumo.

O Rio Grande do Sul é o estado no qual os trabalhadores possuem a maior média de idade (ver Figura 2). Em especial, para o grupo de analistas de TI, o estado apresenta os menores retornos à idade, conforme ilustra a Figura 5. Além disso, o ponto de inflexão dos salários ocorre numa idade mais avançada do que nos outros dois estados. Uma possível explicação é o fato de que os polos tecnológicos abordados no Rio Grande do Sul estão associados a atividades mais tra- 
dicionais, em que há uma busca menos intensa por investimento do trabalhador em atualização profissional. Além disso, por se tratar de polos ligados a atividades mais tradicionais, observa-se o maior grau de discriminação salarial feminina no conjunto de ocupações mais amplo. Já no Paraná, onde ocorrem os maiores retornos à idade e escolaridade, também ocorre a menor desvantagem salarial das mulheres.

\section{Considerações Finais}

Este artigo apresenta um estudo a respeito da mão de obra empregada nas indústrias de transformação e de informação e comunicação dos polos tecnológicos da região sul. O objetivo é identificar a existência de discriminação salarial feminina e avaliar se a discriminação é menor entre os profissionais que atuam como analistas de TI. Os principais resultados são que a análise estatística sugere a existência de discriminação salarial feminina nos três estados da região sul. De fato, o estudo identifica que, num conjunto abrangente de ocupações da indústria, em média, na região sul como um todo, as mulheres recebem $24,8 \%$ a menos do que os homens, porém as mulheres que atuam como analistas de TI reduzem essa desvantagem para $13,9 \%$. Portanto, o grau de discriminação salarial é menor nas carreiras de análise de TI.

A análise descritiva aponta que, nos três estados, a participação feminina na indústria de transformação e serviços de comunicação e informação fica em torno de 30\%. Para as ocupações de analista de TI, as mulheres são ainda menor proporção, estando em torno de $22 \%$, mas possuem, em média, maior grau de escolaridade do que os homens. Também se verifica que a média salarial dos analistas de TI é maior do que a média salarial do conjunto mais amplo de ocupações dos polos, o que ilustra o prêmio salarial dessa ocupação.

Em termos da análise estatística, são obtidos resultados robustos para o impacto dos atributos de produtividade sobre a formação salarial nos polos e para os analistas de TI. No Paraná, ocorrem os maiores retornos ao tempo no emprego, tanto para o conjunto amplo de ocupações, quanto para os analistas de TI, porém ocorrem os menores retornos à idade. Os maiores retornos à idade do trabalhador são observados em Santa Catarina, que é também onde se recebem os menores retornos ao tempo no emprego. Já no Rio Grande do Sul é onde se obtêm os maiores retornos à escolaridade, tanto ao nível de todas as ocupações, quanto ao nível dos analistas de TI. A maior recompensa à escolaridade se dá ao nível de pós-graduação. Já em Santa Catarina, se obtêm os menores retornos à escolaridade.

O estudo também indica que, no conjunto abrangente de ocupações da indústria de transformação, as mulheres sofrem o maior grau de discriminação no Rio Grande do Sul e o menor grau de discriminação no Paraná. Além disso, nos 
três estados há uma vantagem salarial dos analistas de TI em relação às outras ocupações, e essa vantagem é maior para as mulheres do que para os homens. Por isso, o grau de discriminação salarial observado nas indústrias analisadas apresenta-se menor entre os analistas de TI. Esse perfil da força de trabalho identificado se assemelha ao já verificado na Europa e nos Estados Unidos e é inédito em termos de economia brasileira. No caso específico deste estudo, o Paraná tem o menor gap salarial entre homens e mulheres na área de TI, o que sugere que é nesse estado que as mulheres obtêm o maior prêmio de TI.

Embora não seja o enfoque deste estudo, o modo como as mulheres se inserem nas carreiras mais técnicas do mercado de trabalho (STEM) tem sido explicado em termos de duas perspectivas teóricas concorrentes. Uma delas privilegia o papel do contexto sociocultural como determinante das escolhas das mulheres quanto à carreira profissional. Já outra abordagem enfatiza as características individuais para explicar a atuação profissional. Nesse contexto, a análise de dados que abranja a diversidade sociocultural exibida pelas grandes regiões brasileiras pode gerar insights sobre a adequação de cada uma dessas perspectivas teóricas para explicar a sub-representação feminina em carreiras como a de analista de TI.

\section{Referências}

ANITA BORG INSTITUTE. Chronicle of controversy. 2005. Disponível em: $<$ http://www. anitaborg.org/pressroom/pressreleases_05/responsesall.htm >. Acesso em: 13 dez. 2013.

ASHENFELTER, O.; ROUSE, A. B. Estimates of the economic return to schooling from a new sample of twins. Quarterly Journal of Economics, v. 84, n. 5, p. 157-173, 1998.

ASSOCIAÇÃO NACIONAL DE ENTIDADES PROMOTORAS DE EMPREENDIMENTOS INOVADORES. Portfolio de parques tecnológicos no Brasil. Londrina, dez. 2008. Disponível em: $\quad<$ http://www1.londrina.pr.gov.br/dados/images/stories/Storage/codel/ciencia_ tecnologia/portfolio_parque_tecnologicos_brasil.pdf>. Acesso em: 07 dez. 2013.

BECKER, G. Human capital. 3. ed. Chicago: The University of Chicago Press, 1993. 1957.

. The economics of discrimination. 2. ed. Chicago: The University of Chicago Press,

BEEDE, D. et al. Women in STEM: a gender gap to innovation. Washington, D.C.: U.S. Department of Commerce, Aug. 2011.

BONINI, P.; CEMIN, G. P.; MENEZES, C. E. O. Participação feminina na universidade, na produção e no rendimento médio da Grande Florianópolis. In: ENCONTRO DE EXTENSÃO DA UNIVERSIDADE DO ESTADO DE SANTA CATARINA, 4., 2011, Joinville. Anais eletrônicos... Joinville: Udesc, 2011. Disponível em: <http://www.udesc.br/arquivos/id_ submenu/905/artigo_esag_139.pdf>. Acesso em: 10 mar. 2013. 
BRASIL. Ministério do Trabalho e Emprego. Programa de Disseminação de Estatísticas do Trabalho. Microdados da RAIS e CAGED. 2011. Disponível em: <http://pdet.mte.gov.br/ microdados-rais-e-caged>. Acesso em: 31 out. 2013.

CARD, D. Estimating the return to schooling: progress on some persistent econometric problems. Econometrica, v. 65, n. 9, p. 1127-60, 2001.

CARD, D.; KRUEGER, A. Does school quality matter? Returns to education and the characteristics of public schools in the United States. Journal of Political Economy, v. 100, n. 1, p. 1-40, 1992.

CARIS, T.; HAYO, B. Female labor force participation in Arab countries: the role of identity. Marburg, Germany: Universities of Aachen, 2012. (Joint Discussion Paper Series in Economics, n. 41-2012).

CARVALHO, S. S. M.; CHAVES, C. V. Polos tecnológicos e desenvolvimento regional. In: ENCONTRO NACIONAL DE ECONOMIA, 35., 2007, Recife. Anais... Recife: Anpec, 2007.

CECCO, J.; ELLIA, J. P. If you seduce a straight person, can you make them gay? Issues in biological essentialism versus social constructionism in gay and lesbian identities. New York: The Haworth Press, 1993.

CLOSING the gap. The Economist, Special Report, Nov. 26 ${ }^{\text {th }}$, 2011. Disponível em: < http:// www.economist.com/node/21539928 > . Acesso em: 05 set. 2013.

DEY, J.G.; HILL, C. Behind the pay gap. Washington, D.C.: American Association of University Women Educational Foundation, Apr. 2007.

GARDEAZABAL, J.; A. UGIDOS. More on identification in detailed wage decompositions. Review of Economics and Statistics, v. 86, n. 1, p. 1034-1036, 2004.

GENDER and education: nature plus nurture. The Economist, Mar. $7^{\text {th }}, 2015 \mathrm{~b}$. Disponível em: <http://www.economist.com/news/leaders/21645734-girls-do-better-boys-school-anduniversity-both-can-still-improvesometimes > . Acesso em: 10 mar. 2015.

GENDER, education and work: the weaker sex. The Economist, Mar. $7^{\text {th }}, 2015 \mathrm{a}$. Disponível em: <http://www.economist.com/news/international/21645759-boys-are-being-outclassedgirls-both-school-and-university-and-gap > . Acesso em: 10 mar. 2015.

GIUBERTI, A.C.; MENEZES-FILHO. N. Discriminação de rendimentos por gênero: uma comparação entre o Brasil e os Estados Unidos. Economia Aplicada, v. 8, n. 3, p. 369-383, 2005 .

HECKMAN, J. J.; LOCHNER, L. J.; TODD, P. E. Fifty years of Mincer earnings regressions. Cambridge: NBER, May 2003. (Working paper, n. 9732).

IBGE. Comissão Nacional de Classificação. Introdução à Classificação Nacional de Atividades Econômicas - CNAE versão 2.0. Disponível em: < http://concla.ibge.gov.br/images/concla/ documentacao/CNAE20_Introducao.pdf>. Acesso em: 10 jun. 2013.

JANN, B. The Blinder-Oaxaca decomposition for linear regression models. The Stata Journal, v. 8 , n. 4 , p. 453-479, 2008. 
LANGDON, D. et al. Stem: good jobs now and for the future. Washington D.C.: U.S. Department of Commerce, 2011.

LETA, J. As mulheres na ciência brasileira: crescimento, contraste e um perfil de sucesso. Estudos Avançados, v. 17, n. 49, p. 271-284, set./dez. 2003.

LOUREIRO, P. R. A. Uma resenha teórica e empírica sobre economia da discriminação. Revista Brasileira de Economia, Rio de Janeiro, v. 57, n. 1, p. 125-157, 2003.

MARINI, M. M. Sex and gender: what do we know? Sociological Forum, v. 5, n. 1, p. 95-120, 1990.

MINCER, J. Schooling, experience, and earnings. In: Education, experience, and the distribution of earnings and employment: an overview. Cambrigde, MA: NBER Press, 1974. p. 71-94.

OAXACA, R. Male-female wage differentials in urban labor markets. International Economic Review, v. 62, n. 1, p. 693-709, 1973.

OAXACA, R.; RANSON, M. R. Identification in detailed wage decompositions. The Review of Economics and Statistics, v. 81, n. 2, p. 154-157, 1999.

On discrimination and the decomposition of wage differentials. Journal of Econometrics, v. 61, n. 1, p. 5-21, Mar. 1994.

PEREIRA, R.A. Panorama setorial da tecnologia da informação 2010, São Paulo: Sebrae, 2010.

RIO GRANDE DO SUL. Secretaria do Planejamento, Mobilidade e Desenvolvimento Regional. Atlas Socioeconômico do Rio Grande do Sul. Disponível em: < http:// www.atlassocioeconomico.rs.gov.br/conteudo.asp? cod menu filho $=807 \mathcal{E}$ cod menu $=805$ Etipo_menu=POPULAÉcod_conteudo $=1610 \geq$. Acesso em: 12 jun. 2013.

SANTA CATARINA. Secretaria de Desenvolvimento Regional. Escolha a Regional. Disponível em: <http://www2.spg.sc.gov.br/institucional/regionais>. Acesso em: 02 jul. 2013.

SCHULTZ, T. W. O capital humano: investimento em educação e pesquisa. Rio de Janeiro: Zahar Editores, 1973.

TRAUTH, E. M. Odd girl out: an individual differences perspective on women in the It profession. Information Technology and People, v. 15, n. 2, p. 98-118, 2002.

TRAUTH, E. M.; QUESENBERRY, J. Gender and the information technology workforce: issues of theory and practice. In: YOONG, P.; HUFF; S. (Ed.). Managing IT professionals in the internet age. Hersey, PA: Idea Group Publishing, 2007. p. 18-36.

TRAUTH, E. M.; QUESENBERRY, J. L.; MORGAN, A. J. Understanding the under representation of women in it: toward a theory of individual differences. In: ACM SIGMIS COMPUTER PERSONNEL RESEARCH CONFERENCE, 2004, New York. Proceedings... New York: ACM Press, 2004.

TRAUTH, E. M.; QUESENBERRY, J. L.; YEO, B. The influence of environmental context on women in the IT workforce. In: GALLIVAN, J. M.; MOORE, E.; YAGER, S. (Ed.). Proceedings 
of the 2005 ACM SIGMIS CPR Conference on Computer Personnel Research. New York: ACM Press, 2005. p. 24-31.

WAJCMAN, J. Feminism confronts technology. Pennsylvania: The Pennsylvania University Press, 1991.

WILLIS, R. J. Wage determinants: a survey and reinterpretation of human capital earnings functions. In ASHENFELTER, O.; LAYARD, R. (Ed.). Handbook of Labor Economics. Elsevier Science Publisher, 1986. p. 526-602.

Apêndice A - Caracterização dos polos tecnológicos analisados

Tabela 1 - Municípios que formam as regiões metropolitanas dos polos tecnológicos

\begin{tabular}{|c|c|}
\hline \multicolumn{2}{|r|}{ Santa Catarina } \\
\hline Florianópolis & $\begin{array}{l}\text { Águas Mornas, Angelina, Anitápolis, Antônio Carlos, Biguaçu, } \\
\text { Florianópolis, Governador Celso Ramos, Palhoça, Rancho } \\
\text { Queimado, Santo Amaro da Imperatriz, São Bonifácio, São } \\
\text { José, São Pedro de Alcântara. }\end{array}$ \\
\hline Blumenau & Blumenau, Gaspar, Ilhota, Luis Alves, Pomerode. \\
\hline Joinville & $\begin{array}{l}\text { Araquari, Barra do Sul, Barra Velha, Garuva, Itapoá, Joinville, } \\
\text { São Francisco do Sul, São João do Itaperiú. }\end{array}$ \\
\hline \multicolumn{2}{|r|}{ Paraná } \\
\hline Curitiba & $\begin{array}{l}\text { Curitiba, Pinhais, São José dos Pinhais, Mandirituba, Colombo, } \\
\text { Campo Largo. }\end{array}$ \\
\hline Maringá & Maringá, Campo Mourão, Paranavaí, Sarandi e Umuarama. \\
\hline Londrina & $\begin{array}{l}\text { Londrina, Apucarana, Arapongas, Cambé, Cornélio Procópio, } \\
\text { Ibiporã, Jandaia do Sul, Rolândia. }\end{array}$ \\
\hline Região Oeste & $\begin{array}{l}\text { Cascavel, Foz do Iguaçu, Marechal Cândido Rondon, Media- } \\
\text { neira e Toledo. }\end{array}$ \\
\hline Sudoeste & Pato Branco, Francisco Beltrão e Dois Vizinhos. \\
\hline \multicolumn{2}{|r|}{ Rio Grande do Sul } \\
\hline Porto Alegre & $\begin{array}{l}\text { Alvorada, Cachoeirinha, Eldorado do Sul, Glorinha, Gravataí, } \\
\text { Guaíba, Porto Alegre, Santo Antônio da Patrulha, Triunfo, Via- } \\
\text { mão. }\end{array}$ \\
\hline Canoas & $\begin{array}{l}\text { Araricá, Campo Bom, Dois Irmãos, Estância Velha, Esteio, Ivoti, } \\
\text { Nova Hartz, Nova Santa Rita, Novo Hamburgo, Portão, São } \\
\text { Leopoldo, Sapiranga, Sapucaia do Sul. }\end{array}$ \\
\hline
\end{tabular}


conclusão.

Caxias do Sul Antônio Prado, Bento Gonçalves, Boa Vista do Sul, Campestre da Serra, Carlos Barbosa, Caxias do Sul, Coronel Pilar, Cotiporã, Fagundes Varela, Farroupilha, Flores da Cunha, Garibaldi, Guabiju, Guaporé, Ipê, Montauri, Monte Belo do Sul, Nova Araçá, Nova Bassano, Nova Pádua, Nova Prata, Nova Roma do Sul, Paraí, Protásio Alves, Serafina Corrêa, União da Serra, Veranópolis, Vila Flores, Vista Alegre do Prata.

Fontes: Elaboração própria a partir de Pereira (2011), Rio Grande do Sul (2013) e Santa Catarina (2013).

Tabela 2 - Parques tecnológicos nos polos selecionados

\begin{tabular}{|c|c|c|c|}
\hline Região & $\begin{array}{l}\text { Parques } \\
\text { tecnológicos }\end{array}$ & $\begin{array}{l}\text { Início de } \\
\text { operação }\end{array}$ & $\begin{array}{c}\text { Principais setores de } \\
\text { atuação das empresas } \\
\text { participantes }\end{array}$ \\
\hline \multicolumn{4}{|c|}{ Rio Grande do Sul } \\
\hline Porto Alegre & TecnoPuc & $08 / 2000$ & $\begin{array}{l}\text { Biotecnologia, meio am- } \\
\text { biente, energia, eletrôni- } \\
\text { ca, TI. }\end{array}$ \\
\hline Caxias do Sul & Trinopolo & $10 / 2004$ & TI. \\
\hline \multirow{3}{*}{ Canoas } & Valetec & $01 / 2005$ & $\begin{array}{l}\text { Meio ambiente, nanotec- } \\
\text { nologia, novos materiais, } \\
\text { eletrônica, TI. }\end{array}$ \\
\hline & $\begin{array}{l}\text { Parque tecnológico } \\
\text { Ulbra }\end{array}$ & $07 / 2004$ & Energia, biotecnologia, TI. \\
\hline & $\begin{array}{l}\text { TecnoSino (polo de } \\
\text { informática) - São } \\
\text { Leopoldo }\end{array}$ & 1997 & \\
\hline \multicolumn{4}{|c|}{ Paraná } \\
\hline Londrina & $\begin{array}{l}\text { Parque tecnológico de } \\
\text { Londrina Francisco } \\
\text { Sciarra (PTL) }\end{array}$ & $12 / 2003$ & $\begin{array}{l}\text { Biotecnologia, agrone- } \\
\text { gócios, TI, telecomunica- } \\
\text { ções, software. } \\
\end{array}$ \\
\hline Maringá & $\begin{array}{l}\text { Parque tecnológico de } \\
\text { Maringá (Tecnoparq) }\end{array}$ & $06 / 2002$ & $\begin{array}{l}\text { Biotecnologia, agronegó- } \\
\text { cios, energia. } \\
\end{array}$ \\
\hline Curitiba & Tecnoparque Curitiba & $04 / 2008$ & $\begin{array}{l}\text { Biotecnologia, novos ma- } \\
\text { teriais, TI, telecomunica- } \\
\text { ções, software. }\end{array}$ \\
\hline Oeste & $\begin{array}{l}\text { Parque tecnológico } \\
\text { Itaipu (PTI) }\end{array}$ & $12 / 2003$ & $\begin{array}{l}\text { Meio ambiente, serviços } \\
\text { de turismo, energia, TI, } \\
\text { software. }\end{array}$ \\
\hline
\end{tabular}


conclusão.

\begin{tabular}{|c|c|c|c|}
\hline Sudoeste & \begin{tabular}{|l|} 
Parque tecnológico de \\
Pato Branco (PTPB)
\end{tabular} & 03/1998 & $\begin{array}{l}\text { Agronegócios, energia, } \\
\text { eletrônica, TI, software. }\end{array}$ \\
\hline \multicolumn{4}{|c|}{ Santa Catarina } \\
\hline \multirow[b]{2}{*}{ Florianópolis } & $\begin{array}{l}\text { Parque tecnológico } \\
\text { Alfa }\end{array}$ & 08/1995 & $\begin{array}{l}\text { Nanotecnologia, energia, } \\
\text { eletrônica, telecomunica- } \\
\text { ções, software. }\end{array}$ \\
\hline & Sapiens Parque & $04 / 2006$ & $\begin{array}{l}\text { Energia, TI, meio ambien- } \\
\text { te, bioengenharia, média } \\
\text { e audiovisual, serviços de } \\
\text { turismo, serviços do co- } \\
\text { nhecimento. }\end{array}$ \\
\hline Blumenau & ParqueBLU & 2005 & $\begin{array}{l}\text { Têxtil, metal-mecânica, } \\
\text { serviços médicos. }\end{array}$ \\
\hline \multirow{2}{*}{ Joinville } & $\begin{array}{l}\text { Parque de inovação } \\
\text { tecnológica da região } \\
\text { de Joinville (Tecville) }\end{array}$ & $\begin{array}{l}\text { 04/2008 } \\
\text { (projeto) }\end{array}$ & $\begin{array}{l}\text { Biotecnologia, meio am- } \\
\text { biente, TI, design, quími- } \\
\text { ca-farmacêutica. }\end{array}$ \\
\hline & \begin{tabular}{|l|} 
Parque de inovação \\
tecnológica de Joinvil- \\
le (PITJ)
\end{tabular} & $\begin{array}{l}\text { 07/2002 } \\
\text { (projeto) }\end{array}$ & $\begin{array}{l}\text { Biotecnologia, agronegó- } \\
\text { cios, meio ambiente. }\end{array}$ \\
\hline
\end{tabular}

Fonte: Elaboração própria a partir de Associação Nacional de Entidades Promotoras de Empreendimentos Inovadores (2008). 


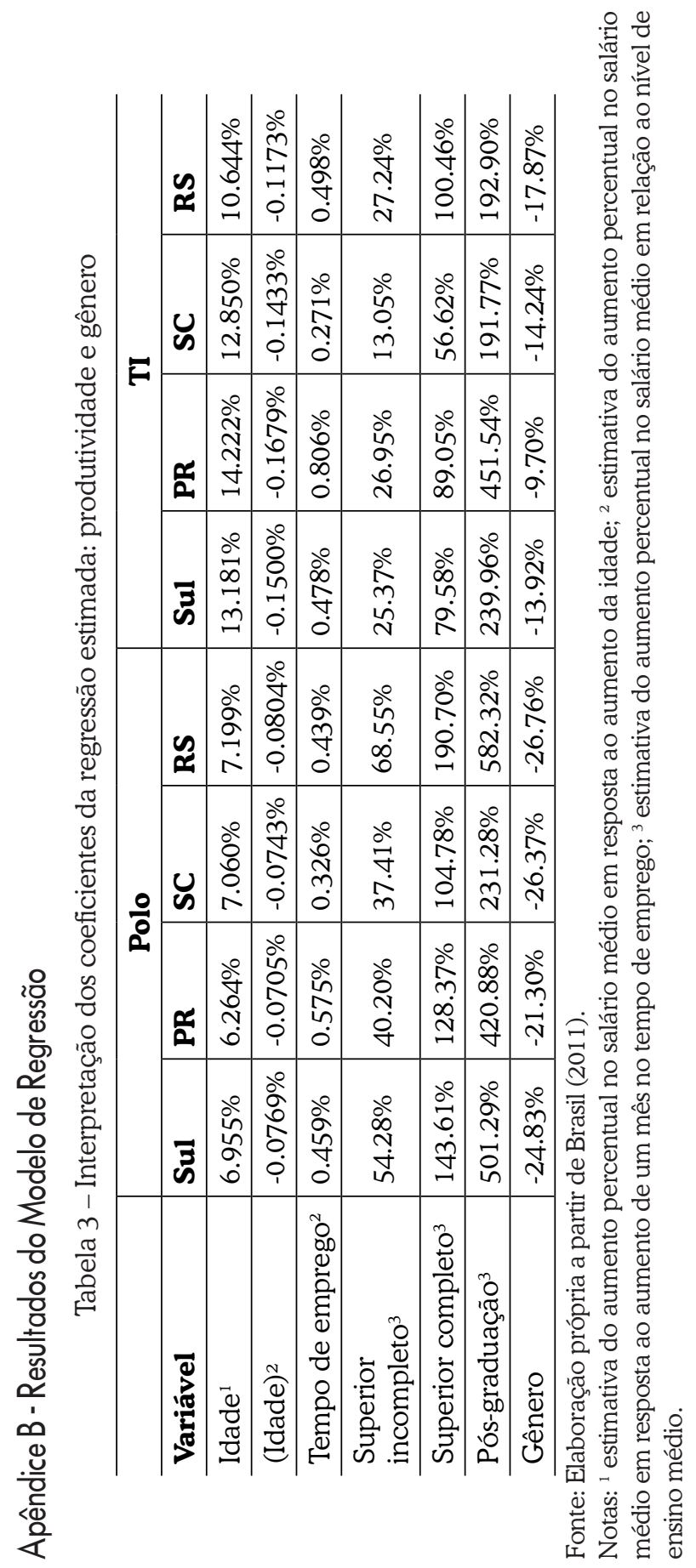

BONINI, P.; POZZOBON, F. Discriminação Salarial Feminina e o Prêmio Salarial de TI... 
Tabela 4 - Coeficientes estimados para a análise cruzada dos estados

\begin{tabular}{|c|c|c|c|c|}
\hline \multicolumn{5}{|c|}{ Polo } \\
\hline \multirow[b]{2}{*}{ Variável } & \multicolumn{2}{|c|}{ Base SC } & \multicolumn{2}{|c|}{ Base PR } \\
\hline & Coeficiente & valor $p^{*}$ & Coeficiente & valor $\boldsymbol{p}^{*}$ \\
\hline Idade & 0.0705999 & 0 & 0.0626378 & 0 \\
\hline idade 2 & -0.0007434 & 0 & -0.0007053 & 0 \\
\hline Tempemp & 0.0032629 & 0 & 0.0057539 & 0 \\
\hline Sexo & -0.3061089 & 0 & -0.2395582 & 0 \\
\hline Supinc & 0.3177967 & 0 & 0.337882 & 0 \\
\hline Sup & 0.7167829 & 0 & 0.8257893 & 0 \\
\hline Pos & 1.197792 & 0 & 1.65035 & 0 \\
\hline drg2 & -0.0278662 & 0.641 & 0.0278662 & 0.641 \\
\hline (PR)idade & -0.0079621 & 0.037 & 0.0079621 & 0.037 \\
\hline (PR)idade2 & 0.000038 & 0.504 & -0.000038 & 0.504 \\
\hline (PR)tempemp & 0.0024909 & 0 & -0.0024909 & 0 \\
\hline (PR)supinc & 0.0200853 & 0.151 & -0.0200853 & 0.151 \\
\hline (PR)sup & 0.1090063 & 0 & -0.1090063 & 0 \\
\hline (PR)pos & 0.4525581 & 0.001 & -0.4525581 & 0.001 \\
\hline (PR)sexo & 0.0665507 & 0 & -0.0665507 & 0 \\
\hline drg3 & -0.1045966 & 0.091 & -0.0767305 & 0.172 \\
\hline (RS)idade & 0.0013886 & 0.724 & 0.0093507 & 0.009 \\
\hline (RS)idade2 & -0.0000602 & 0.3 & -0.0000982 & 0.064 \\
\hline (RS)tempemp & 0.0011276 & 0 & -0.0013633 & 0 \\
\hline (RS)supinc & 0.2042818 & 0 & 0.1841965 & 0 \\
\hline (RS)sup & 0.3503331 & 0 & 0.2413268 & 0 \\
\hline (RS)pos & 0.7225399 & 0 & 0.2699818 & 0.018 \\
\hline (RS)sexo & -0.0053039 & 0.65 & -0.0718547 & 0 \\
\hline cons & 2.071204 & 0 & 2.043338 & 0 \\
\hline
\end{tabular}


conclusão.

\section{TI}

\begin{tabular}{l|l|l|l|l}
\hline & \multicolumn{2}{|c|}{ Base SC } & \multicolumn{2}{c}{ Base PR } \\
\hline Variável & Coeficiente & valor $\boldsymbol{p}^{*}$ & Coeficiente & valor $\boldsymbol{p}^{*}$ \\
\hline Idade & 0.128502 & 0 & 0.14222 & 0 \\
\hline idade2 & -0.00143 & 0 & -0.00168 & 0 \\
\hline tempemp & 0.00271 & 0 & 0.008057 & 0 \\
\hline Sexo & -0.15366 & 0 & -0.10203 & 0.004 \\
\hline Supinc & 0.122687 & 0 & 0.238609 & 0 \\
\hline Sup & 0.44866 & 0 & 0.636856 & 0 \\
\hline Pos & 1.070809 & 0 & 1.707543 & 0 \\
\hline drg2 & -0.60899 & 0.005 & 0.557354 & 0.007 \\
\hline (SC)idade & 0.013718 & 0.283 & -0.01372 & 0.283 \\
\hline (SC)idade2 & -0.00025 & 0.186 & 0.000245 & 0.186 \\
\hline (SC)tempemp & 0.005347 & 0 & -0.00535 & 0 \\
\hline (SC)supinc & 0.115922 & 0.01 & -0.11592 & 0.01 \\
\hline (SC)sup & 0.188195 & 0 & -0.1882 & 0 \\
\hline (SC)pos & 0.636734 & 0.013 & -0.63673 & 0.013 \\
\hline (SC)sexo & 0.051637 & 0.191 & -0.05164 & 0.191 \\
\hline drg3 & 0.344251 & 0.041 & 0.858387 & 0 \\
\hline (RS)idade & -0.02207 & 0.028 & -0.03578 & 0.01 \\
\hline (RS)idade2 & 0.00026 & 0.071 & 0.000506 & 0.012 \\
\hline (RS)tempemp & 0.002274 & 0 & -0.00307 & 0 \\
\hline (RS)supinc & 0.118208 & 0.003 & 0.002286 & 0.958 \\
\hline (RS)sup & 0.246792 & 0 & 0.058597 & 0.16 \\
\hline (RS)pos & 0.003839 & 0.984 & -0.6329 & 0.007 \\
\hline (RS)sexo & -0.04322 & 0.17 & -0.09486 & 0.03 \\
\hline Fo Er & 0.017 & \\
\hline
\end{tabular}

Fonte: Elaboração própria a partir de Brasil (2011).

Nota: "valor $p$ é o menor nível de significância com o qual se passa a rejeitar $\mathrm{H}_{0}$.

Recebido em: 15/01/2015.

Aceito em: 19/10/2015. 